\title{
Effects of Thallium Stress on Photosynthesis,
}

\section{Chlorophyll Fluorescence Parameters and Antioxidant Enzymes Activities of Coix Lacryma-jobi}

\author{
Gaozhong Pu, Denan Zhang, Danjuan Zeng, Guangping Xu and Yuqing Huang \\ Research Center for Eco-Environmental Sciences, Guangxi Key Laboratory of Plant Conservation and Restoration Ecology in Karst \\ Terrain, Guangxi Institue of Botany, Guangxi Zhuang Autonomous Region and Chinese Academy of Sciences, Guilin 541006, China
}

\begin{abstract}
Levels of $\mathrm{Tl}$ (Thallium) in soil from 0 (control) to $50 \mu \mathrm{g} / \mathrm{L}$ through $0.2,0.5,1$ and $2.5 \mu \mathrm{g} / \mathrm{L}$ were directly and positively correlated to levels of $\mathrm{Tl}$ in plant tissue, the accumulation being maximum in roots, intermediate in leaves and minimum in stems. Thallium, especially at higher concentrations, adversely affected photosynthesis (as judged based on chlorophyll fluorescence parameters), suggesting inhibition of photo-activation of PSII (Photosystems II), and also decreased the rate of photosynthesis, the rate of transpiration and stomatal conductivity drastically. Exposure to $\mathrm{Tl}$ also increased the activity of CAT (Catalase) (except at 1 $\mu \mathrm{g} / \mathrm{L}$ ) and POD (Peroxidase) (except at $0.2 \mu \mathrm{g} / \mathrm{L}$ ), suggesting that the antioxidant systems in Coix lacryma-jobi were the main contributors of CAT and SOD (Superoxide Dismutase) and that the tolerance of C. lacryma-jobi to Tl is mainly due to this induced antioxidant machinery.
\end{abstract}

Key words: Antioxidant enzyme, Coix lacryma-jobi L., chlorophyll fluorescence, Thallium, wetland.

\section{Introduction}

$\mathrm{Tl}$ (Thallium) is a relatively rare and non-essential metal, which occurs mainly as monovalent and trivalent thallium oxide. Because it is highly toxic to animals, plants and microorganisms, $\mathrm{Tl}$ has attracted increasing concern [1]. Extensive mining of ore that contains $\mathrm{Tl}$, smelting and burning of Tl-containing fossil fuels are the major sources of anthropogenic dispersion of $\mathrm{Tl}$ in the environment [2]. Although we now have some understanding of the environmental geochemistry and ecotoxicology of $\mathrm{Tl}$, the mechanism of $\mathrm{Tl}$ toxicity is not entirely clear.

Because $\mathrm{Tl}^{+}$and $\mathrm{K}^{+}$have similar ionic radii [3], they can interfere with $\mathrm{Na}^{+} / \mathrm{K}^{+}$ATPase and pyruvate kinase and induce oxidative stress in plants [2]. Thus, plants can readily accumulate $\mathrm{Tl}^{+}$from soil, and $\mathrm{Tl}$ thus enters the food chain and, in turn, the bodies of animals and human beings. In general, plants accumulate Tlmainly

Corresponding author: Yuqing Huang, professor, main research field: ecology. in leaves and roots and to some extent in stems and fruits, whose extent and the pattern of accumulation being dependent on the species and on soil characteristics $[4,5]$. Plant cells contain considerable amounts of $\mathrm{K}^{+}$in the chloroplasts, and $\mathrm{Tl}$ pollution can often lead to the accumulation of $\mathrm{Tl}$ in the chloroplasts, which may lead to physiological effects on photosynthesis and the activity of antioxidant enzymes because $\mathrm{Tl}^{+}$can interfere with $\mathrm{Na}^{+} / \mathrm{K}^{+}$ATPase, pyruvate kinase and membrane phospholipids [2]. It is therefore important to understand the effect of $\mathrm{Tl}$ on the physiological parameters and antioxidant enzymes activity in plants. Unfortunately, there is little research in this area.

Coix lacryma-jobi L. or Job's tears, is an andropogonoid grass native to tropical Asia that is widely adventive and considered invasive [6]. The species is widely cultivated as a food plant and as a medicinal plant in East Asia and Southeast Asia. Earlier studies on the species were focused mainly on its biological characteristics, medicinal components 
and their efficacy, and on its genetics and genomics [7-11]. Despite being widely cultivated, little is known about the effects of $\mathrm{Tl}$ pollution on this plant. Therefore, the objective of the present study was to monitor the responses of chlorophyll fluorescence, photosynthetic parameters and the activity of antioxidant enzymes in C. lacryma-jobi to different levels of $\mathrm{Tl}$ stress and also to highlight the uptake and translocation of $\mathrm{Tl}$ in the plant.

\section{Material and Methods}

\subsection{Test Soil and Thallium Concentrations}

The test soil was a red clay. Surface soil $(0-20 \mathrm{~cm})$ and water were sampled from the garden of the Guangxi Institute of Botany, and the basic physiochemical properties of the samples were analyzed (Table 1). Plastic containers (tackle boxes, each $35 \mathrm{~cm}$ in diameter and $50 \mathrm{~cm}$ tall) were filled with the test soil (5 $\mathrm{kg}$ of soil in each box) and $4 \mathrm{~L}$ of water was added to each box. The treatments comprised a control (no added $\mathrm{Tl}$ ) and thallium chloride to give five concentrations of $\mathrm{Tl}$, namely $0.2,0.5,1,2.5$ and 50 $\mu \mathrm{g} / \mathrm{L}$.

\subsection{Culture and Harvest for Plant}

During the growing period of C. lacryma-jobi, the height of water was always maintained at $4 \mathrm{~L}$ of water in soil. After being cultivated for 120 days, chlorophyll fluorescence parameters, photosynthetic gas exchange parameters, and the activity of antioxidant enzymes were determined. After that, the plants were harvested; carefully washed with tap water and deionized water; separated into leaves, stems and roots; the parts cut into bits with stainless steel scissors; and dried at $40{ }^{\circ} \mathrm{C}$ for $48 \mathrm{~h}$ for elemental analysis. Total $\mathrm{Tl}$ in the plant material was estimated, following the protocol of Srivastava and D'Souza [12], after digesting the oven-dried samples (100 mg each).

\subsection{Photosynthetic Parameters}

Chlorophyll fluorescence parameters and photosynthetic gas exchange parameters were determined by the method described by Lichtenthaler [13] using a LI-6400XT portable photosynthesis system (Li-Cor, Inc., Lincoln, NE, USA) and a portable fluorometer (Monitoring-PAM, Walz, Germany) separately. The rate of photosynthesis (Pn), the rate of transpiration (Tr), intercellular concentration of $\mathrm{CO}_{2}(\mathrm{Ci})$ and stomatal conductivity (Gs) were measured from the middle region of the topmost fully expanded leaf at $25{ }^{\circ} \mathrm{C}$ under a light intensity of $1,200 \mu \mathrm{mol} \cdot \mathrm{m}^{-2} \cdot \mathrm{s}^{-1}$, relative humidity of $40 \%$, and $\mathrm{CO}_{2}$ concentration of $370 \mu \mathrm{mol} \cdot \mathrm{mol}^{-1}$. The topmost fully expanded leaves of treated and control plants were first light- and dark-adapted for $20 \mathrm{~min}$ to obtain $\mathrm{F}$ and $\mathrm{Fo}$. The values of $\mathrm{Fm}^{\prime}$ and $\mathrm{Fm}$ (maximum fluorescence yield of light and dark-adapted leaves, respectively) were calculated with a saturation pulse, and the maximum photosystem II quantum yield was then calculated using the following formula: $(\mathrm{Fm}-\mathrm{Fo}) / \mathrm{Fm}=\mathrm{Fv} / \mathrm{Fm}$. The effective quantum yield of PSII (Photosystems II), or Y(II), was calculated, as suggested by Genty [14], using the following formula: $\mathrm{Y}(\mathrm{II})=(\mathrm{Fm}-\mathrm{F}) / \mathrm{Fm}$. All measurements were the averages from five plants in each replication and were recorded during 8:00-11:00 a.m.

\subsection{Antioxidant Enzymes Activities}

The activities of SOD, POD and CAT were assayed by following the protocols of Asthir [15] with a slight modification. Leaves (samples of $0.3 \mathrm{~g}$ each) were homogenized in $5 \mathrm{~cm}^{3}$ of ice-cold $50 \mathrm{mM}$ phosphate buffer (pH 6.5 for POD and SOD and 7.5 for CAT).

Table 1 Basic physiochemical properties of tested soil and water.

\begin{tabular}{llllllllll}
\hline \multicolumn{4}{c}{ Soil } \\
\hline PH & TN $(\mathrm{g} / \mathrm{kg})$ & TP $(\mathrm{g} / \mathrm{kg})$ & $\mathrm{TK}(\mathrm{g} / \mathrm{kg})$ & $\mathrm{T}-\mathrm{Tl}(\mathrm{mg} / \mathrm{kg})$ & $\mathrm{PH}$ & $\mathrm{DO}(\mathrm{mg} / \mathrm{L})$ & $\mathrm{SpC}(\mu \mathrm{s} / \mathrm{cm})$ & $\mathrm{Ca}^{2+}(\mathrm{mg} / \mathrm{L})$ & $\mathrm{T}-\mathrm{Tl}(\mu \mathrm{g} / \mathrm{L})$ \\
6.50 & 1.17 & 0.80 & 0.78 & 0.002 & 7.38 & 1.56 & 235.00 & 53.00 & 0.005 \\
\hline
\end{tabular}


Table 2 Concentrations of $\mathrm{Tl}$ in dry giant reed plants after 4-month cultivation.

\begin{tabular}{llll}
\hline $\begin{array}{l}\text { Concentration } \\
(\mu \mathrm{g} / \mathrm{L})\end{array}$ & $\begin{array}{l}\text { Leaves } \\
(\mathrm{mg} / \mathrm{kg})\end{array}$ & $\begin{array}{l}\text { Shoots } \\
(\mathrm{mg} / \mathrm{kg})\end{array}$ & Roots $(\mathrm{mg} / \mathrm{kg})$ \\
\hline 0.00 & $0.02^{* *}$ & $0.03^{* *}$ & $0.33^{*}$ \\
0.20 & $0.19^{* *}$ & $0.20^{*}$ & $0.62^{*}$ \\
0.50 & $1.32^{* *}$ & $0.42^{*}$ & $2.13^{* *}$ \\
1.00 & $2.13^{*}$ & $0.66^{*}$ & $3.48^{* *}$ \\
2.50 & $2.46^{*}$ & $1.35^{* *}$ & $4.09^{* *}$ \\
50.00 & $3.26^{* *}$ & $2.08^{* *}$ & $5.23^{* *}$ \\
\hline
\end{tabular}

Note: Data with a single star $(*)$ indicate a significant difference at $P<0.05$ among different $\mathrm{Tl}$ treatments in the same part of plants, and with double stars $(* *)$ indicate a significant difference at $P<0.001$.

The extracts were centrifuged at $10,000 \mathrm{~g}$ for $20 \mathrm{~min}$ at $0-4{ }^{\circ} \mathrm{C}$ in a Beckmann refrigerated centrifuge, and the supernatants were used for the enzyme activity assays.

\subsection{Data Analysis}

All data were statistically analyzed using SPSS (Statistical Product and Service Solutions). The accumulated amounts of $\mathrm{Tl}$ were expressed as mean \pm SD (Standard Deviation) of four replicates, and ANOVA (Analysis of Variance) was applied to assess significant differences $(P<0.05$, unless stated otherwise), if any, among the various treatments.

\section{Results and Discussion}

\subsection{Accumulation of $T l$}

In ascending order of the amount of $\mathrm{Tl}$ accumulated, the plant parts were stems, leaves and roots, and the accumulation was positively correlated to the $\mathrm{Tl}$ concentration (Table 2). The maximum accumulation in roots occurred at $50 \mu \mathrm{g} / \mathrm{L}$ of $\mathrm{Tl}$ and its translocation factor was up to 1.02 , the actual amounts being 2.08 $\mathrm{mg} / \mathrm{kg}$ in stems, $3.23 \mathrm{mg} / \mathrm{kg}$ in leaves and $5.23 \mathrm{mg} / \mathrm{kg}$ in roots (Table 2). Earlier reports indicate that when grown on Tl-contaminated soils, many crops, such as Brassica napus, Triticum turgidum and Biscutella laevigata, may contain $\mathrm{Tl}$ at concentrations above the maximum permissible limits $[5,16,17]$. Compared to these species, the TF of C. lacryma-jobi was higher, indicating that $C$. lacryma-jobi can accumulate more Tl than these species because it has a higher capacity for $\mathrm{Tl}^{+}$uptake, given that the uptake of the chemically similar $\mathrm{Tl}^{+}$and $\mathrm{K}^{+}$are linked $[5,18]$.

\subsection{Photosynthetic Parameters}

The relative chlorophyll content of C. lacryma-jobi varied with $\mathrm{Tl}$ concentration, but the only statistically significant difference was observed between the 50 $\mu \mathrm{g} / \mathrm{L}$ treatments and $0,0.2,1$ or $2.5 \mu \mathrm{g} / \mathrm{L}$ treatments (Fig. 1). Chlorophyll fluorescence parameters showed that $\mathrm{Tl}$, especially at higher concentrations, affected photosynthesis adversely (Fig. 1). At $50 \mu \mathrm{g} / \mathrm{L}, \mathrm{Tl}$ not only decreased the relative chlorophyll content but also decreased the primary photochemical efficiency of PS II (Fv/Fm), Fv/Fo and yield. These results indicated that PSII reaction centers were seriously damaged at $\mathrm{Tl}$ concentrations of $50 \mu \mathrm{g} / \mathrm{L}$ and that $\mathrm{Tl}$ at that concentration inhibited the photo-activation of PSII because a decline in $\mathrm{Fv} / \mathrm{Fm}$ and $\mathrm{Fv} / \mathrm{Fo}_{0}$ indicated a disturbance in or damage to the photosynthetic apparatus $[19,20]$. One possible reason for the reduced chlorophyll fluorescence in the present study is a functional disorder in antenna complexes that increased $\mathrm{Fo}$ and thereby decreased $\mathrm{Fv} / \mathrm{Fm}$ and $\mathrm{Fv} / \mathrm{Fo}$ and in turn, photosynthesis [21]. At the same time, once the structure of PSII was destroyed, photosynthesis decreased, and the light energy absorbed by leaves could not be converted into chemical energy, the result being inhibition of the initial photosynthesis reaction [22].

The stress induced by $\mathrm{Tl}$ decreased the Pn, Tr and Gs in the leaves drastically as compared to the control, but increased the $\mathrm{Ci}$ at $0.2 \mu \mathrm{g} / \mathrm{L}$ and $50 \mu \mathrm{g} / \mathrm{L}$ (Fig. 2). 

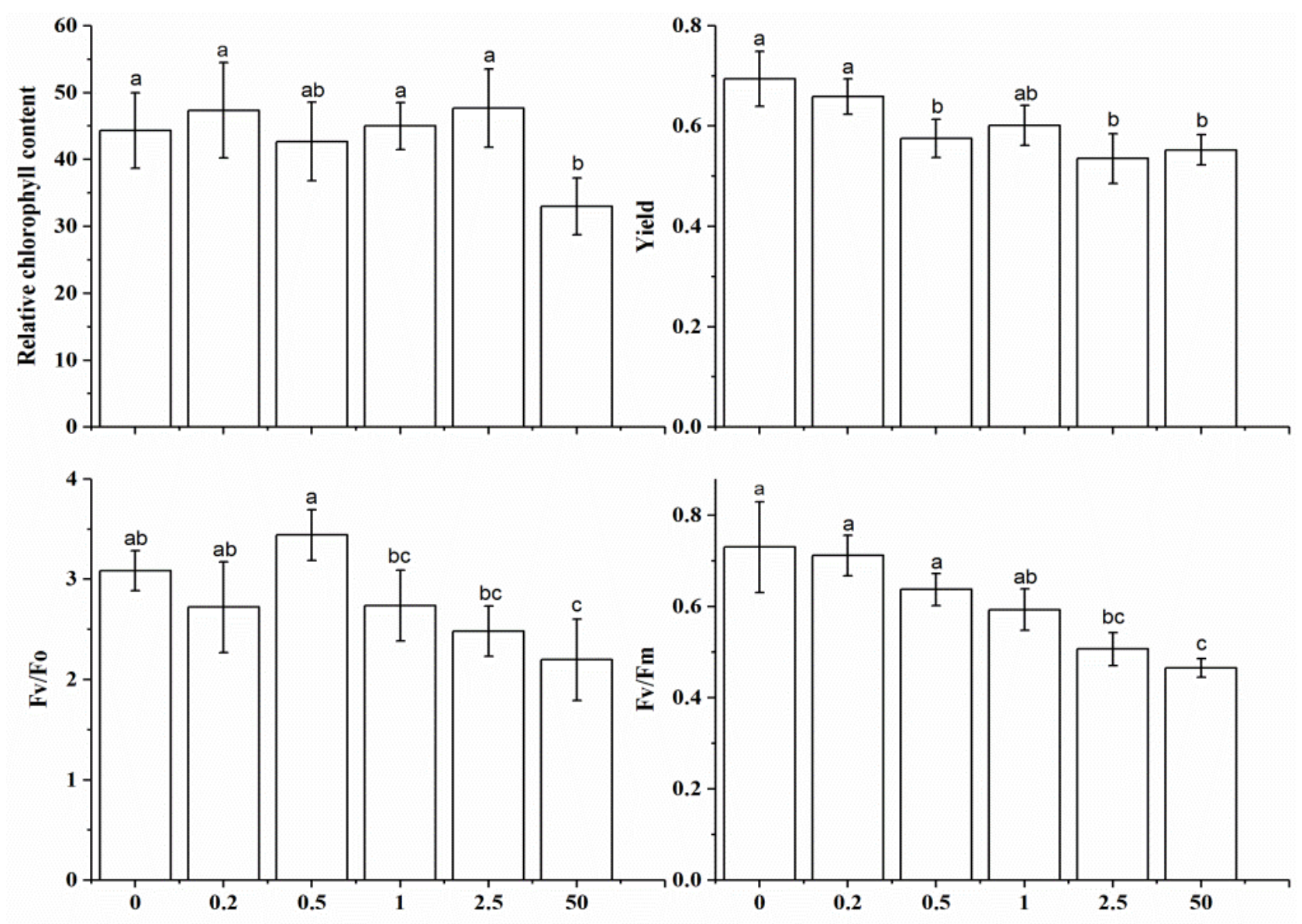

Tl Concentration $\left(\mu \mathrm{g} \cdot \mathbf{L}^{-1}\right)$

Fig. 1 Chlorophyll fluorescence parameters of $C$. lacryma-jobi in the five concentrations of Tl treatments. Different lowercase letters on the top of the bars denote significant differences $(P<0.05)$ among different $\mathrm{Tl}$ treatments.
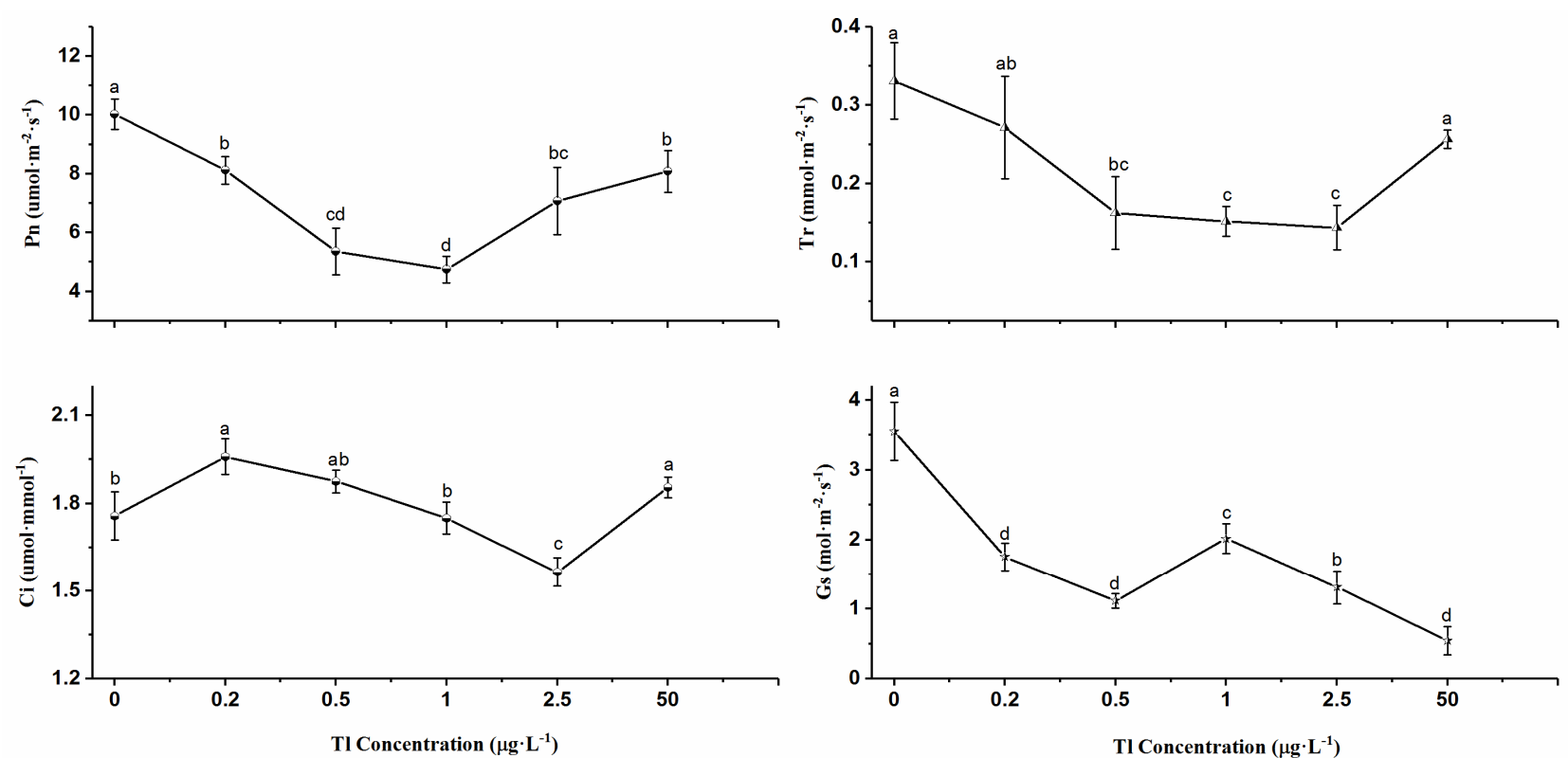

Fig. 2 Gas exchange parameters of $C$. lacryma-jobi under different level Tl conditions. Different lowercase letters on the top of the bars denote significant differences $(P<0.05)$ among different $T 1$ treatments. 


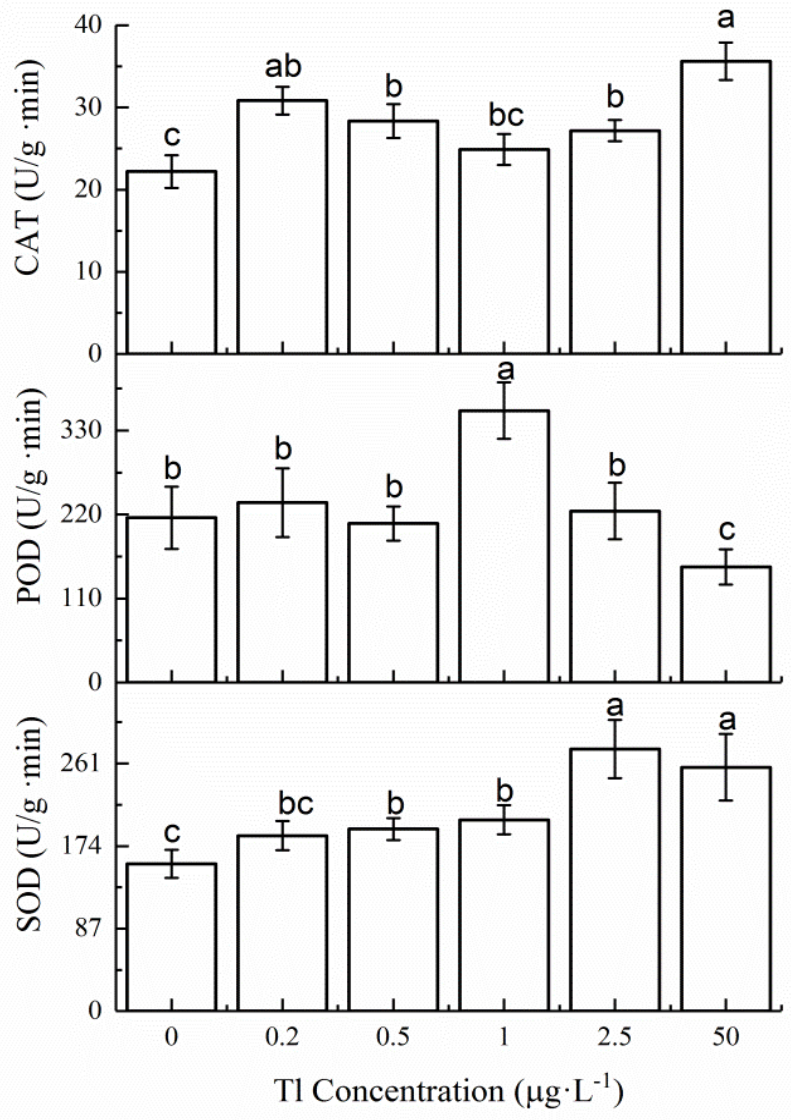

Fig. 3 Effect of TI stress on SOD, COD and CAT activities in leaf of $C$. lacryma-jobi. Different lowercase letters on the top of the bars denote significant differences $(P<0.05)$ among different $T 1$ treatments.

Two earlier studies indicated that one of the main reasons for heavy-metal toxicity came from the disturbed water relations in plants [23, 24]. Therefore, the authors propose that the decrease in Pn is due to the inhibition of various steps in the Hill reaction, the Calvin cycle and $\mathrm{CO}_{2}$ fixation $[24,25]$. At the same time, the $\mathrm{Ci}$ was significantly increased at $0.2 \mu \mathrm{g} / \mathrm{L}$ and $50 \mu \mathrm{g} / \mathrm{L}$ (Fig. 2), probably as the combined effect of stomatal conductance, chlorophyll content, and functioning of the photosynthetic apparatus - reduction in the rate of $\mathrm{CO}_{2}$ exchange cannot be explained fully by any single factor [26].

\subsection{Antioxidant Enzymes Activities}

In plants exposed to $\mathrm{Tl}$, the activity of CAT (except at $1 \mu \mathrm{g} / \mathrm{L}$ ) and of COD (except at $0.2 \mu \mathrm{g} / \mathrm{L}$ ) increased significantly compared to that in the control. However, POD activity was maximum at $1 \mu \mathrm{g} / \mathrm{L}$ and minimum at $50 \mu \mathrm{g} / \mathrm{L} \mathrm{Tl}$ (Fig. 3). In general, antioxidant enzymes are the common means in plants to regulate the ROS produced during metabolic processes [27]. Authors' results show that the activity of CAT and SOD increased under $\mathrm{Tl}$ stress, suggesting that the conversion of $\mathrm{H}_{2} \mathrm{O}_{2}$ increases under $\mathrm{Tl}$ stress, given that CAT converts $\mathrm{H}_{2} \mathrm{O}_{2}$ into water and molecular $\mathrm{O}_{2}$ (Oxygen) and catalyzes the dismutation of $\mathrm{O}_{2}^{-}$to $\mathrm{H}_{2} \mathrm{O}_{2}$ and $\mathrm{O}_{2}$. One possible reason is that $\mathrm{Tl}$ stress reduces the capacity of $C$. lacryma-jobi to assimilate carbon, thereby triggering an increase in photosynthetic electron flux to molecular oxygen, resulting in increased production of superoxide, namely hydrogen peroxide [28]. The activity of POD increased only at $1 \mu \mathrm{g} / \mathrm{L}$, suggesting that it is not the most important $\mathrm{H}_{2} \mathrm{O}_{2}$-scavenging enzyme in C. lacryma-jobi. And the activity of POD decreased at $50 \mu \mathrm{g} / \mathrm{L}$, suggesting that POD can be damaged if exposed to a high level of $\mathrm{Tl}$ stress. 


\section{Conclusion}

Taken together, these results show that the accumulation of $\mathrm{Tl}$ in leaves, stems and roots of $C$. lacryma-jobi increased with increase in $\mathrm{Tl}$ concentrations in soil-water, pointing to the greater capacity of the species for $\mathrm{K}^{+}$uptake. The variation in photosynthetic parameters, including relative chlorophyll content, chlorophyll fluorescence parameters and photosynthetic gas exchange parameters, suggests that photo-activation of PSII was inhibited by $\mathrm{Tl}$ toxicity. However, the antioxidant systems in C. lacryma-jobi, mainly CAT and SOD, moderated the adverse effects of $\mathrm{Tl}-$ and, in turn, those of reactive oxygen species_on C. lacryma-jobi, because $\mathrm{Tl}$ triggers the activation of those systems.

\section{Acknowledgment}

This study was supported by the Natural Science Foundation of Guangxi Province (2013GXNSFEA053001; 2015GXNSFEA139001), Guangxi Scientific and Technological Project (Guikezhong1598014-3) and the Fund of Guangxi Key Laboratory of Plant Conservation and Restoration Ecology in Karst Terrain (GKB15-A-33).

\section{References}

[1] Gomez-Gonzaleza, M. A., Garcia-Guineaa, J., Labor, F., and Garrido, F. 2015. "Thallium Occurrence and Partitioning in Soils and Sediments Affected by Mining Activities in Madrid Province (Spain)." Science of the Total Environment 536 (12): 268-78.

[2] Siegel, B. Z., and Siegel, S. M. 1976. "Effect of Potassium on Thallium Toxicity in Cucumber Seedlings: Further Evidence for Potassium-Thallium Ion Antagonism." Bioinorganic Chemistry 6 (4): 341-5.

[3] Belowitz, R., and Donnell, M. J. O. 2013. "Ion-Selective Microelectrode Measurements of $\mathrm{Tl}(+)$ and $\mathrm{K}(+)$ Transport by the Gut and Associated Epithelia in Chironomus Riparius." Aquatic Toxicology 138-9 (8): $70-80$.

[4] Alshaal, T., Domokos-Szabolcsy, E., Marton, L. J., Katai-Balogh, P., Elhawat, N., El-Ramady, H., et al. 2013. "Phytoremediation of Bauxite-Derived Red Mud by Giant Reed." Environmetal Chemistry Letters 11 (3): 295-302.
[5] Renkema, H., Koopmans, A., Hale, B., and Berkelaar, E. 2015. "Thallium and Potassium Uptake Kinetics and Competition Differ between Durum Wheat and Canola." Environmental Scienceand Pollution Research 22 (3): 2166-74.

[6] Leseberg, C. H., and Duvall, M. R. 2009. "The Complete Chloroplast Genome of Coixlacryma-jobiand a Comparative Molecular Evolutionary Analysis of Plastomes in Cereals." Journal of Molecular Evolution 69 (4): 311-8.

[7] Han, Y., Wang, G., Liu, Z., Liu, J., Yue, W., Song, R., et al. 2010. "Divergence Incentromere Structure Distinguishes Related Genomes in Coix Lacryma-jobiand its Wild Relative." Chromosoma 119 (1): 89-98.

[8] Woo, J. H., Dapeng, L., Orita, H., Coulter, J., Tully, E., Kwon, T. K., et al. 2007. "Coix Seed Extract, A Commonly Used Treatment for Cancer in China, Inhibits NFкB and Protein Kinase C Signaling." Cancer Biology \& Therapy 6 (12): 2005-11.

[9] Lu, Y., Zhang, B., Jia, Z., Wu, W., and Lu, Z. 2011. "Hepatocellular Carcinoma HepG2 Cellapoptosis and Caspase- 8 and Bcl-2 Expression Induced by Injectableseed Extract of Coix Lacryma-jobi." Hepatobiliary \& Pancreatic Diseases International 10 (3): 303-7.

[10] Cai, Z. X., Liu, H. J., Xie, W. J., and Jin, W.W. 2013. "Research Advances in Coix L. Biology." Crops 2013 (2): 16-22.

[11] Cai, Z. X., Liu, H. J., He, Q. Y., Pu, M. W., Chen, J., Lai, J. S., et al. 2014. "Differential Genome Evolution and Speciation of Coix Lacryma-jobi L. and Coix Aquatica Roxb. Hybrid Guangxi Revealed by Repetitive Sequence Analysis and Fine Karyotyping." BMC Genomics 15 (1): 1025.

[12] Srivastava, S., and D'Souza, S. F. 2010. "Effect of Variable Sulfur Supply on Arsenic Tolerance and Antioxidant Responses in Hydrilla Verticillata (L.f.) Royle." Ecotoxicology and Environmental Safety 73: 1314-22.

[13] Lichtenthaler, H. K., Langsdorf, G., Lenk, S., and Buschamann, C. 2005. "Chlorophyll Fluorescence Imaging of Photosynthetic Activity with the Flash-Lamp Fluorescence Imaging System." Photosynthetica 43 (3): 355-69.

[14] Asthir, B., Koundal, A., Bains, N. S., and Mann, S. K. 2010. "Stimulation of Antioxidative Enzymes and Polyamines during Stripe Rust Disease of Wheat." Biologia Plantarum 54 (2): 329-33.

[15] Shah, K., and Nahakpam, S. 2012. "Heat Exposure Alters the Expression of SOD, POD, APX and CAT Isozymes and Mitigates Low Cadmium Toxicity in Seedlings of Sensitive and tolerant Rice Cultivars." Plant Physiology 


\section{Enzymes Activities of Coix Lacryma-jobi}

and Biochemistry 57 (3): 106-13.

[16] Pavličková, J., Zbìral, J., Smatanová, M., Houserová, P., Čižmárová, E., Havliková, S., et al. 2005. "Uptake of Thallium from Artificially and Naturally Contaminated Soils into Rape (Brassica napus L.)." Journal of Agricultural and Food Chemistry 53 (8): 2867-71.

[17] Pošćić, F., Marchiol, L., and Schat, H. 2013. "Hyperaccumulation of Thallium is Population-Specific and Uncorrelated with Caesium Accumulation in the Thallium Hyperaccumulator Bisctella Laevigata." Plant and Soil 365 (1): 81-91.

[18] Tremel, A., Masson, P., Sterckeman, T., Baize, D., and Mench, M. 1997. "Thallium in French Agrosystems-I. Thallium Contents in Arable Soils." Environmental Pollution 95 (3): 293-302.

[19] Li, S. L., Yang, W. H., Yang, T. T., Chen, Y., and Ni, W. Z. 2015. "Effects of Cadmium Stress on Leaf Chlorophyll Fluorescence and Photosynthesis of Elsholtzia Argyi-A cadmium Accumulating Plant." International Journal of Phytoremediation 17 (1-6): 85-92.

[20] Wang, Y., Chai, L. Y., Yang, Z. H., Mubarak, H. S., and Tang, C. J. 2016. "Chlorophyll Fluorescence in Leaves of Ficus tikoua Under Arsenic Stress." Bulletin of Environmental Contamination and Toxicology 97 (4): 576-81.

[21] Wang, L., Xu, Y. M., Sun, Y. B., Liang, X. F., and Lin, D. S. 2014. "Identification of Pakchoi Cultivars with Low Cadmium Accumulation and Soil Factors that Affect Their Cadmium Uptake and Translocation." Frontiers of Environmental Science \& Engineering 8 (6): 877-87.

[22] Liu, H. G., Hu, C. X., Sun, X. H., Tan, Q. L., Nie, Z. J., and Hu, X. M. 2010. "Interactive Effects of Molybdenum and Phosphorus Fertilizers on Photosynthetic Characteristics of Seedlings and Grain Yield of Brassica Napus." Plant and Soil 326 (1): 345-53.

[23] Vassilev, A., Vangronsveld, J., and Yordanov, I. 2002. "Cadmium Phytoextraction Present State Biological Bakgrounds Research Needs." Bulgarian Journal of Plant Physiology 28 (3-4): 68.

[24] Haouari, C. C., Nasraoui, A. H., Bouthour, D., Houda, M. D.,Daieb, C. B., Mnai, J., et al. 2012. "Response Oftomato (Solanum Lycopersicon) to Cadmium Toxicity: Growth, Element Uptake, Chlorophyll Content and Photosynthesis Rate.” African Journal of Plant Science 6 (1): 1-7.

[25] Dong, J., Wu, F., and Zhang, G. 2005. "Effect of Cadmium on Growth and Photosynthesis of Tomato Seedlings." Journal of Zhejiang University, Science B 6 (10): 974-80.

[26] Ainsworth, E. A., and Rogers, A. 2000. "The Response of Photosynthesis and Stomatal Conductance to Rising $\left[\mathrm{CO}_{2}\right]$ : Mechanisms and Environmental Interactions." Plant, Cell \& Environment 30 (3): 258-70.

[27] Liu, N., Lin, Z., Guan, L., Gaughan, G., and Lin, G. 2014. "Antioxidant Enzymes Regulate Reactive Oxygen Species during Pod Elongation in Pisum Sativum and Brassica Chinensis." Plos One 9: e87588.

[28] Odjegba, V. J., and Fasidi, I. O. 2007. "Changes in Antioxidant Enzyme Activities in Eichhornia Crassipes (Pontederiaceae) and Pistia Stratiotes (Araceae) under Heavy Metal Stress.” Revista De Biologia Tropical 55 (55): 815-23. 